\title{
ESTIMATION OF ADSORBED ANION CHARGE DENSITY FROM THE ELECTRODE CHARGE-POTENTIAL RELATIONSHIP
}

LOWELL R. MCCOY AND HARRY B. MLARK, JR.

Department of Chemistry, University of Michigan, Ann Arbor, Mich. 48 rof (U.S.A.)

(Feceived June 24th, I966; in revised form December 3oth, r966)

\section{INTRODUCTION}

GIERSI and FRUMKI:2.3 have shown that valuable information concerning the nature of electrode mechanisms can be obtained if the potential of the outer Helmholtz plane, $\psi^{\circ}$, is known as a function of electrode potential. In cases where these studies involve electrode potentials relatively negative to the electrocapillary maximum, and a low concentration of electrolyte, $\psi^{\circ}$ can be calculated from data obtained by GRAHAME4 for sodium fluonde solutions. Such calculations have been made by RUSSELL5 who has listed corresponding values of the electrode potential*, charge, and $\psi^{\circ}$ in tabular form for a number of concentrations of sodium fluoride. In more concentrated solutions and at potentials in the vicinity of, or positive to, the electrocapillary maximum, serious deviations from Russell's values can arise from the adsorption of anions. If the degree of the adsorption is known, corrections can be made for this effect. However, there is little data available in the literature relating the adsorbed anion charge density to electrode potential. It was noted when collecting such data (see acknowledgement) for other studies, that an apparent relationship existed between that degree of anion adsorption for a given electrolyte and the position of its electrode charge-potential curve with respect to a semihypothetical curve representing no anion adsorption. Although the correlation developed on this basis is quite approximate it may offer a basis for estimation of the adsorbed anion charge density in a single experiment to establish the electrode charge-potential curve. The charge-potential curve can be obtained from electrocapillary curves, ${ }^{6}$, differential capacity measurements ${ }^{6}$ or by the potential step method ${ }^{7}$. The correlation also indicates that a substantial degree of adsorption of fluoride may exist at sufficiently positive potentials.

\section{CORRELATION OF ANION ADSORPTION DATA}

Calculation of $\psi^{\circ}$-potentials in the presence of adsorbed anions requires that both the electrode charge and the adsorbed ion charge densities be known. The charge in the diffuse zone, $q^{a}$, is obtained from the difference, and the $\psi^{\circ}$-value can then be calculated from the Gouy-Chapman equation. The procedures and equations employed in these calculations as well as those used in the determination of the adsorbed ion charge have been well summarized by others6.8.9 and, thus, will not be discussed * Shown incorrectly as S.C.E.; should refer to N.C.E. 
here. Figures $x$ and 2 illustrate the electrode charge-potential curves for a number of electrolytes* at $0 . I$ and $I .0 N$ concentrations, respectively. On each curve has been placed small index lines indicating the adsorbed anion charge density, $q^{1}$, for that electrolyte corresponding to a specific electrode charge value. These are shown in $5-\mu \mathrm{C} / \mathrm{cm}^{2}$ intervals, the positions having been obtained by interpolation of graphs in which $q^{1}$ was plotted as a function of electrode charge using the original data. Inspection of $F$ igs. I and 2 shows that rather smooth curves may be drawn through the index lines representing the same values for $q^{i}$ for the various electrolytes and that these curves tend to parallel the curve for potassium or sodium fluoride at electrode potentials negative to $-0.4 \mathrm{~V}$ (N.C.E.). At electrode potentials positive to the latter
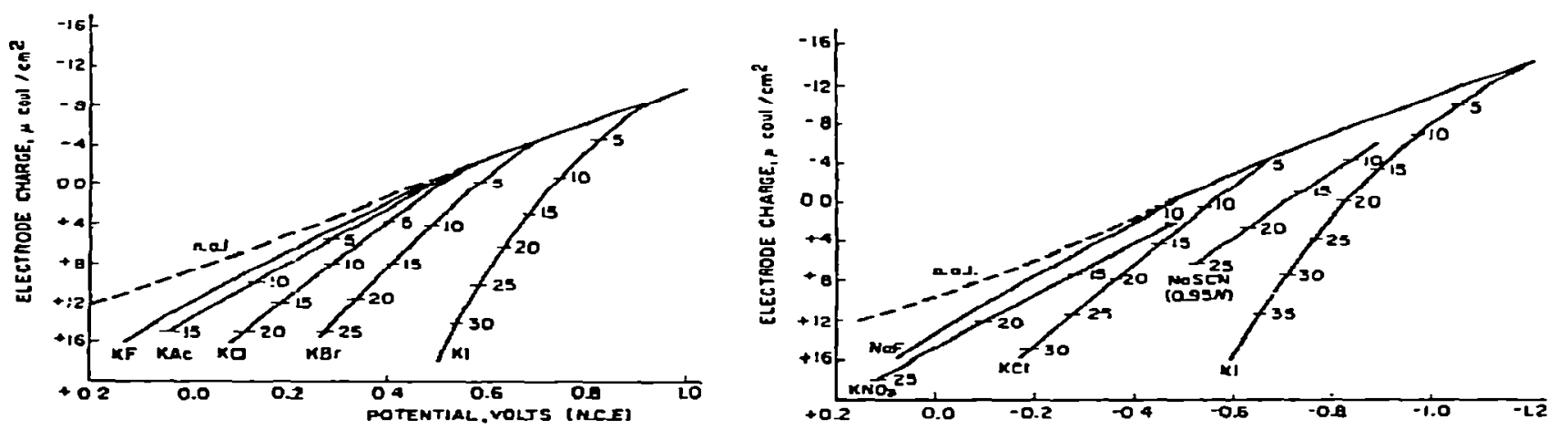

Figs. I-z. Electrode charge-potential carves for: (I) $0.1 \mathrm{~N}$ solns: (2) I.o $N$ solns. Adsorbed charge in $\mu \mathrm{C} \mathrm{cm}-2$.

vaiue, the extrapolated equal adsorbed charge lines cross the curve for the fluoride ion suggesting that adsorption of the fluoride ion may be occurrin $\bar{B}$ in this more positive potential region. A hypothetical non-adsorption line (n.a.l.) was therefore constructed for each concentration, making the positive charge-potential relationship symmetrical at the E.C.M. to the negative charge-potential curves for the fluoride ion. The n.a.l. for potentials positive to the E.C.M. appears as a dotted line in Figs. I and 2 . In the case of o.I $N$ potassium fluoride, the curve was constructed employing the data obtained by GRAFAME 4 . As data for $I .0 N$ potassium fluoride was not available, however, it was necessary to use RusselL's5 extrapolated values for I.o $N$ sodium fluoride. The actual corresponding charge-potential values used in constructing the line representing no adsorption over the entire potential range appear in Table I. Again, inspection of Figs. I and 2 suggests that the lines connecting the same values of $q^{1}$ for the various electrolytes at either concentration tend to follow the dotted n.a.l. in the more positive potential region.

The relationship described above can be viewed more clearly in Figs. 3 and 4. The quantity, $\Delta q$, appearing as the ordinate in these graphs, represents the difference between the electrode charge corresponding to a pair of $q^{1}$ and electrode potential values for a given electrolyte, and the electrode charge taken from the n.a.1. at the same potential. Plotted in this manner. the values of $q^{1}$ for the various electrolytes

\footnotetext{
- Unpnblished detta for KNOa and mixtures of NH,NOb and NHAF yere supplied by R PAYNE. Unpublished datil for NaSCN. was furnished by $R$. PARsovs who also supplied unpublished data for IKCl obtained-by D. Grasase. Data relevant to other salts at 0.1 concn. can be found in ref. Ii.
}

$J$ - Elsctroanal-Ghem. 15 (ig67) $15-20$ 
tend to fall along lines which appear to converge at some positive potential. While the data for potassium nitrate shows a rather poor agreement, the other data presented in Figs. 3 and 4 exhibit a pattern which is remarkably independent of the size and charge of the anions. This correlation is put to a more severe test in Figs. 5 and 6 , in which data for the sodium salts of $\mathrm{CN}^{-}, \mathrm{CNS}-, \mathrm{ClO}_{4}^{-}, \mathrm{ClO}_{3}^{-}$and $\mathrm{BrO}_{3}^{-}$obtained by Wroblow et al.10 have been positioned upon the grid tentatively established in

TABLE 1

CHARGE-POTENTIAI VALUES EMPLOYED TO PREPARE THE "NON"ADSORPTION LINE"

\begin{tabular}{|c|c|c|c|c|c|}
\hline \multicolumn{2}{|c|}{$0 . T N K F$} & \multicolumn{2}{|c|}{$0 . I N K^{\prime} F$} & \multicolumn{2}{|c|}{$0 . T N K F$} \\
\hline$=E *$ & $q$ & $-E=$ & $q$ & $-E^{*}$ & $q$ \\
\hline 1.40 & -16.45 & 0.60 & $-2.6 z$ & 0.144 & $6.5 \mathrm{I}$ \\
\hline 1.30 & -14.79 & 0.50 & -0.59 & 0.094 & $7 \cdot 40$ \\
\hline 1.20 & -13.17 & 0.472 & 0.00 & 0.044 & 8.24 \\
\hline I. Io & -11.57 & 0.394 & $x .6 I$ & -0.006 & 9.12 \\
\hline$x .00$ & -9.95 & 0.344 & 2.62 & -0.056 & 9.95 \\
\hline 0.90 & -8.28 & 0.294 & 3.63 & -0.106 & 1077 \\
\hline 0.80 & $-6.5 \mathrm{I}$ & 0.244 & $4.6 I$ & & \\
\hline 0.70 & $-4.6 x$ & 0.194 & $5 \cdot 5^{8}$ & & \\
\hline
\end{tabular}

\begin{tabular}{|c|c|c|c|c|c|}
\hline \multicolumn{2}{|c|}{$1.0 N N a F$} & \multicolumn{2}{|c|}{ I.o N NaF } & \multicolumn{2}{|c|}{ I.ON $\mathrm{NaF}$} \\
\hline $\bar{E}$ & $q$ & $\overline{-E}$ & $q$ & $-E$ & $q$ \\
\hline I. 4 I 6 & $-16.00 \dagger$ & 0.650 & $-4.2 \mathrm{I}$ & 0.094 & 8.08 \\
\hline 1.295 & $-14.00 t$ & 0.550 & -1.95 & -0.006 & $9.7^{8}$ \\
\hline $1 . x>0$ & - I2.00t & 0.472 & 0.00 & $-0.10_{4}$ & I I. 40 \\
\hline $\begin{array}{l}0.950 \\
0.850\end{array}$ & $\begin{array}{r}-97^{8} \\
-8.08\end{array}$ & $\begin{array}{l}0.394 \\
0.294\end{array}$ & $\begin{array}{r}1.95 \\
+.21\end{array}$ & -0.204 & 13.00 \\
\hline $0.75^{\circ}$ & -6.24 & 0.194 & 6.24 & & \\
\hline
\end{tabular}

* us. N.C.E. † Unpublished data from R. PARsons for I.o N KCl, balance of column from Russell's values for NaFs.
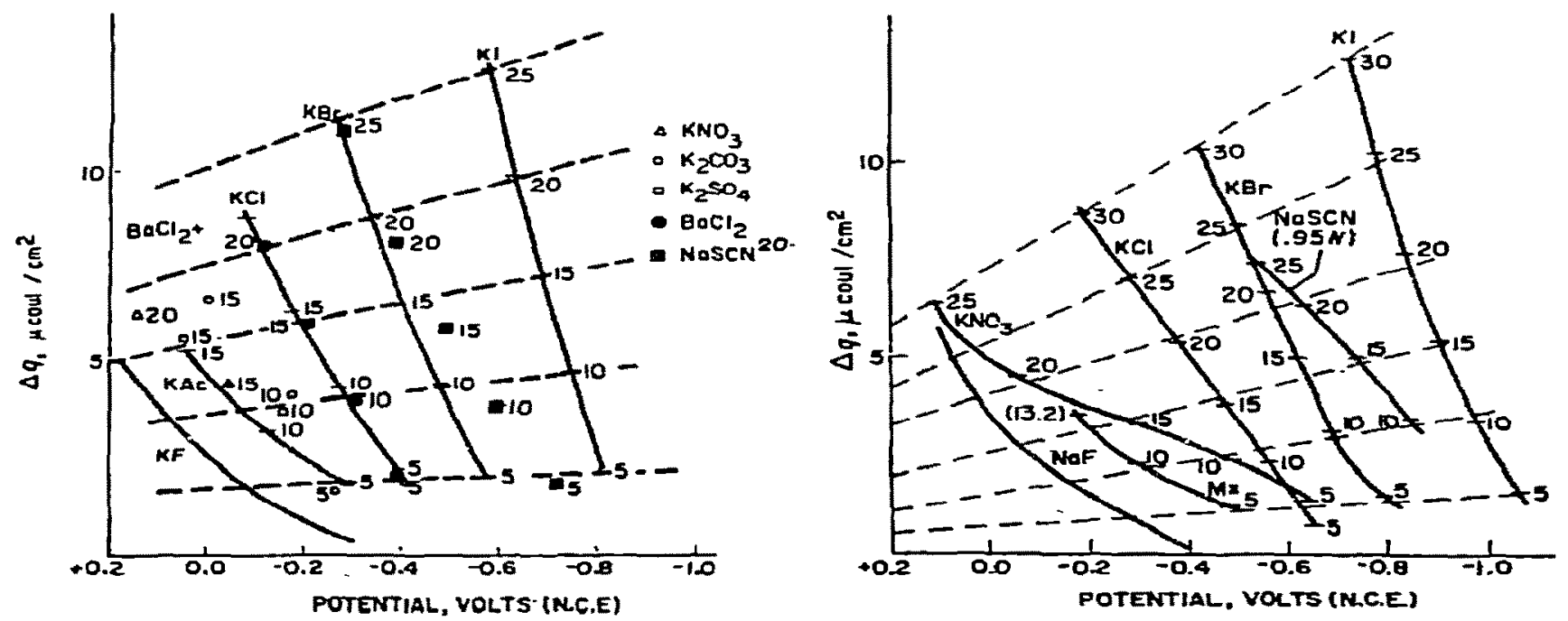

Figs. 3-4. Correlation diagram for: (3) o.I $N$ solns.: (4) r.o $N$ solns.; using data obtained by Gra-

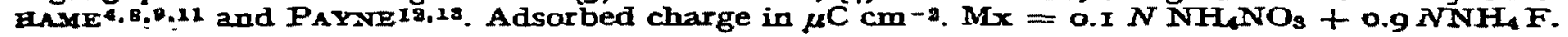


Figs. 3 and 4. These anions are of particular interest because, by their size and complexity, their adsorption characteristics may be expected to differ significantly from those of the halogen ions. It is evident that the correlation obtained with these more complex ions is rather poor. It should be noted in this connection, however, that the data presented in Figs. 5 and 6 were obtained from interfacial tension
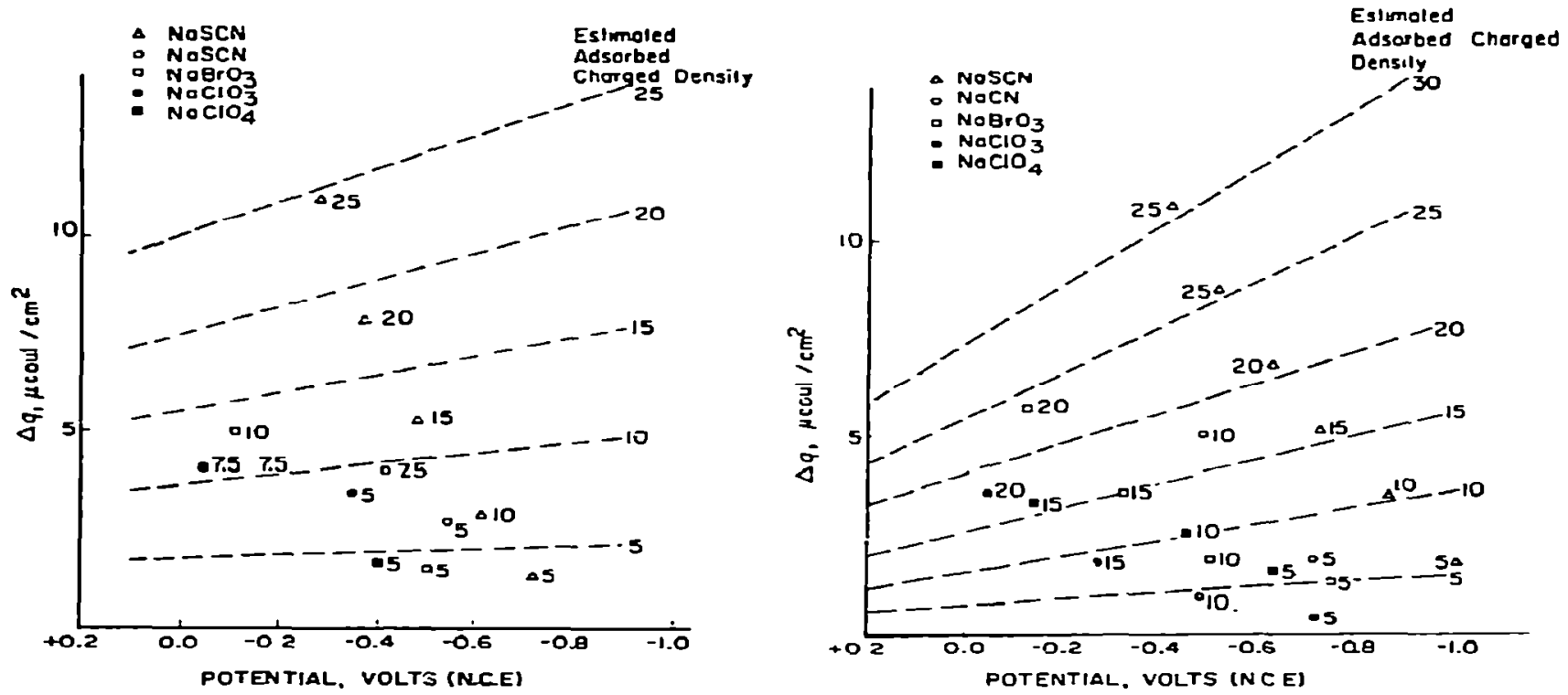

Figs. 5-6. Correlation diagram for: (5) o I $N$ solns.; (6) r.o $N$ solns.; using data obtained by WROBLOWA el al.10.

measurements and that the scatter of the electrode charge-potential data at the more negative electrode potentials (where the curves for all of the salts should coincide in the relative absence of anion adsorption) is considerably greater than that observed in the data shown in Figs. I and 2 (where the values were established from differential capacitance measurements). The charge-potential curve for o.I $N$ NaSCN is particularly disturbing in this respect as the cathodic branch of the curve relative to the E.C.M. differs greatly from that of the other salts in this region. The potential of the E.C.M. of about $-0.605 \mathrm{~V}$ (corrected to N.C.E.) found by WRoBlowa et al.10 for NaSCN differs significantly from the value of $-0.628 \mathrm{~V}$ found by GRAFAME AND SODERBERG ${ }^{11}$ for KSCN. In this potential range, little difference would be expected between the values for the sodium and potassium salts. At least part, though certainly not all, of the instances of poor correlation observed in Figs. 5 and 6 may therefore result from a shift of the charge-potential curves along the potential axis. As noted above, however, the large scatter of the data at more negative potentials precludes any attempts at re-positioning the curves along the potertial scale. There is reason to question, therefore, whether at least part of the lack of correlation observed in Figs. 5 and 6 in contrast to Figs. 3 and 4 may lie in the lack of precision in the data obtained by Wroblowa et al.10.

Inspection of Figs. 3 and 4 indicates that adsorption of fluoride ion may occur to a sabstantial degree at sufficiently positive potentials (or electrode charge). While this possibility has been discussed by a number of authors4,12-16, generally

J. Electroarál. Chem., 15 (1967) 15-20 
accepted values of adsorbed charge densities of this ion as a function of electrode potential or charge are wholly lacking. PAYNE ${ }^{12,13}$ has examined this subject in detail with regard to his data for mixed systems of the nitrate or perchlorate ions and the fluoride ion and has considered the possibility of competitive adsorption. Figure 4 would indicate that such a competition would be expected.

DIsCUSSION

In view of the very approximate nature of the correlation presented in Figs. 3-6, any attempt to present a theoretical basis for its existence would be at best premature and none will be attempted here. Some commentary upon the implications of the method itself may, however, be made. It appears preferable to conduct this, or any other attempt at a correlation, using solutions at the same activity rather than at the same concentration, but it was felt that there was insufficient published data to warrant this effort. The assumption of a symmetrial "non-adsorption line" has considerable theoretical significance. As noted above, this line was chosen as an extension of the cathodic portion of the charge-potential curve for the fluoride ion for the simple reason that lines connecting equal adsorbed charges appeared to parallel such an extension. On the other hand, the absence of a precise correlation of data at more cathodic potentials prevented any attempt to describe this course as truly symmetrical. MoHILNER ${ }^{12}$ has pointed out that, if symmetry were assumed, this would require also that, in the absence of adsorbed ions, the differential inner capacitance be a symmetric even function of the charge upon the electrode; a situation contrary to that found by GRAHAME in his calculations of the sodium fluoride data. However, the inner capacitance values were calculated by GRAHAME 4 with the assumption that adsorption of the fluoride ion was absent, and agreement between the theoretical and experimental capacitance values calculated on this basis was not too satisfactory at more positive electrode charge values. This point has also been discussed critically by PARsons 18 in connection with an earlier treatment of inner capacitance as a function of electrode charge by MACDONALD ${ }^{19}$, which assumed such a symmetrical relationship. A simple test may be applied by observing that, if adsorption of fluoride ion were actually present and if a symmetrical charge-potential

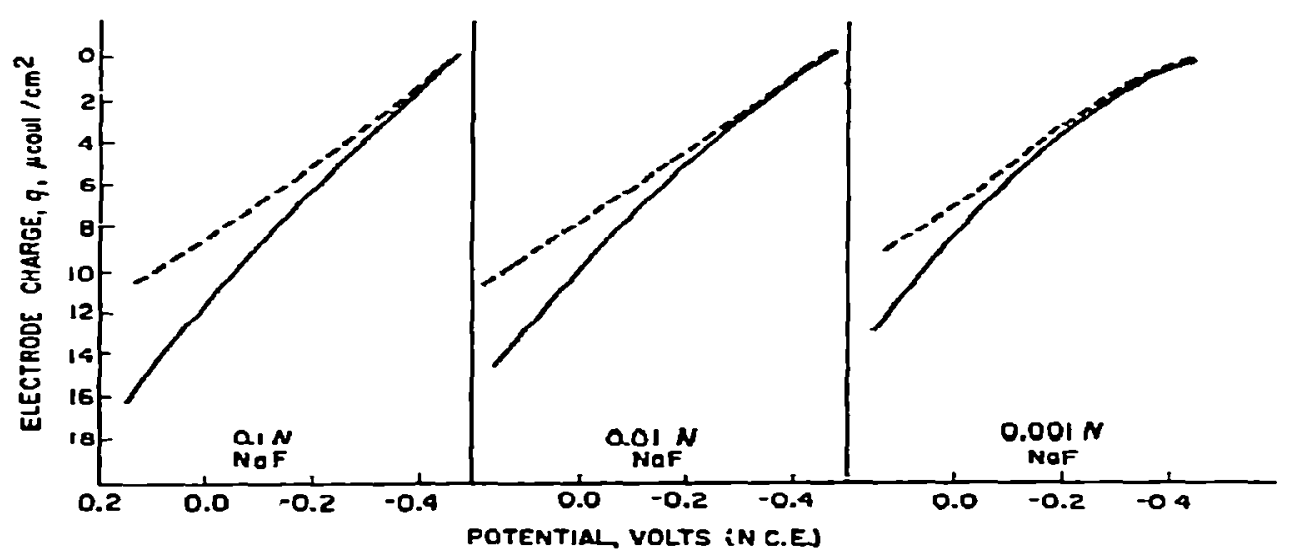

Fig. 7. Symmetry of electrode charge-potential curves at the E.C.M. as a function of the concn. of NaF. ( Experimental + $q-V$ curve: $(--)$ symmetrical extensicn of $-q-V$ curve. 
relationship should in fact exist in the absence of adsorption, the hypothetical anodic extension of the charge-potential relationship symmetrical at the E.C.M. with respect to the experinuental cathodic portion of the curve should exhibit a greater coincidence with the experimental cathodic portion of the curve as the concentration of sodium fluoride decreases. Figure 7 prepared from Russell's 5 tables indicates that such a trend is observed.

SUMALARY

A correlation, based upon available data for a number of electrolytes at o.I and I.o $N$ concentrations, may permit adsorbed anion charge densities to be estimated as a function of electrode potential by comparing the experimentally-determined charge-potential relationship for a previously uninvestigated electrolyte with a semihypothetical curve representing no anion adsorption. The results are believed sufficiently precise to permit the calculation of approximate $\psi^{\circ}$-potentials for use in kinetic studies. The correlation indicates that the adsorption of fluoride ion may be substantial at sufficiently positive potentials.

\section{ACFNOWLEDGEMENTS}

The authors are indebted to Dr. Roger PARsons for much of the data included in this study, to Dr. RICHARD PAYNe for data relating to potassium nitrate and ammonium nitrate-fluoride mixtures and to the Department of Chemistry, Amberst College, which supplied copies of a number of the Technical Reports to the Office of Naval Research prepared by Dr. DAvID GRAmanIE and his co-workers. This research was supported in part by a grant from the U.S. Army Research Office, Durham, Contract No. Da-3I-I24-ARO-D-284.

\section{REFERENCES}

I L. Grerst, Trans. Symp. Elechyode Processes, Philadelphia, Pa.. 1959. p. 109.

2 A. FRUMKIN, ibid., p. I.

3 A. Fruskin, Advan. Electrochem. Electrochem. Eng., I (1961) 65.

4 D. C. Grahaire, J. Am. Címem. Soü., 76 (1954) 4819.

5 C. D. RUSSELL. $J$. Electroanal. Chem.. 6 (1963) 486.

6 P. Delahay. Double Layer and Eledrode Kinetics, Interscience Publishers, Inc., New York, r965, chaps. $2-5$.

7 R. A. OSTERYOUNG, private communication, 1966.

3 D. C. GRahaite and B. A. Soderberg. J. Chem. Phys., 22 (I954) 449.

9 D. C. Grahante, Ghem. Rev., 4I (I947) 44 I.

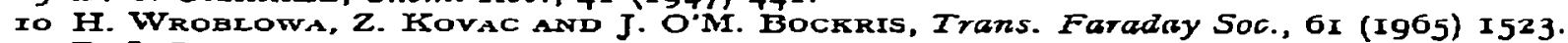

II D. C. Gratane and B. A. Soderberg, Technical Report No. I4 to the Office of Naval Research, Feb. 18, 1954.

12 R. Payne. J. Pr̈ys. Chem., 69 (1965) 4113.

I3 R. PAYNE, ibid., 70 (1966) 204.

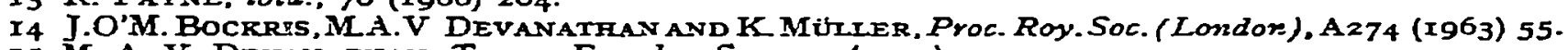

I5 M. A. V. Devinathan, Trans. Faraday Soc., 50 (1954) 373.

I6 J. R. MacDonald and C. A. Barlow, JR., J. Chem. Phys., 36 (I962) 3026

I7 D. M. MOHILNER, private communication, I966.

I8 R Parsons, Adyan. Electrochem. Electrochem. Eng., I (I96I) 6.

Ig J. R. MacDonat.D, J. Chem. Phys., 22 (1954) 4857.

20 R. Parsons AND P. C. Symons, private communication, 1966.

21 R. PArsons, R PAYNe AND J. LAwrence, private communication, 1966. 